\title{
THE ROLE OF PSYCHOLOGICAL READINESS FOR DOCTOR-PATIENT COMMUNICATION IN THE PROFESSIONAL DEVELOPMENT OF MEDICAL STUDENTS
}

\author{
Anna Zakharova ${ }^{1 *}$, Evgeni Nikolaev ${ }^{2}$, Elena Zaitseva ${ }^{3}$, Tamara Talanova ${ }^{3}$, Nadezhda $^{3}$ \\ Lantsova $^{3}$, Lyubov Romanova ${ }^{3}$ \\ ${ }^{1}$ Associate Prof., Chuvash State University, RUSSIA, E-mail: zaharova_an@mail.ru \\ ${ }^{2}$ Prof. Dr., Chuvash State University, RUSSIA \\ ${ }^{3}$ Associate Prof., Chuvash State University, RUSSIA, \\ ${ }^{*}$ Corresponding author
}

\begin{abstract}
The problem of the formation of the communicative competence of a professional is at the heart of today's psychological science. Communicative competence as a factor of professional success is important, and, thus, scientists have a significant interest to the problems of communicative competence of an individual, but researches of this phenomenon in relation to the various psychological characteristics of the individual, including the features of coping behavior, are not yet sufficient. Within the framework of this article the authors explore the communicative competence of university students through such structural components as: the level of communication skills-building; emotional intelligence, expressed in the ability to master their own emotions, recognizing the other's emotions and influencing them; coping strategies, manifested as an inclination to use strategies related to mastering their own emotions in difficult stressful situations, coping with communicative difficulties. The article highlights the results of an empirical research targeted at the psychological features of the communicative competence of students studying medicine at a Russian regional university. The study involved combined total sample size of 120 medical students with a high academic performance, the interviews with teachers and the analysis of documentation. The study revealed the number of problematic issues related to the communicative competence of medical students. A number of sample size students lack their communicative competence: they provided communicative difficulties, low emotional intelligence (according to the Hall's Emotional Intelligence Quotient), and maladaptive coping strategies (according to the Lazarus "Way of Coping" Questionnaire). All these problematic issues may become an obstacle when building the process of a doctor-to-patient communication, as well as to attaining an advanced proficiency standard. The research offers new insights planned to be used for improving the educational process at the university, for building a psychological program in the university environment with the students' communicative competence being its target.
\end{abstract}

Keywords: doctor-patient communication, medical students, role of psychological readiness, Russian regional university

\section{INTRODUCTION}

The analysis of scientific publications reveals a number of approaches to the problem of the communicative competence structure, as well as to the study of its structure, the definition of components reflecting 
behavioral, personal and cognitive factors affecting the success of communicative interaction in the professional field of soon-to-be specialists studying at the university.

A number of studies have found that a high level of emotional intelligence development contributes to success in various spheres of human life, such as law, education, medicine. Moreover, the development of employees' abilities in the communicative and emotional sphere has a positive impact on their professional activities (Macnamara J., 2018; Morova, N.S. et al, 2017; Morova, N.S. et al, 2017; Solovieva O. V., Bondarenko O.S., 2018; Nasilenko L.A., 2013; Tretyakov V.S., Ignatenko A.A., 2012; Petrovskaya A.S., 2007., Zakharova, A.N. et al, 2018; Zakharova, A.N. et al, 2020). The analysis of various specialists on the communicative competence and emotional intelligence as its structural element shows that currently most researches are devoted to socio-humanitarian and pedagogical professions, while there are clearly not enough studies revealing the specifics of the manifestation of these phenomena in medical specialties.

Throughout history, the doctor-patient relationship has been recognized as having an important therapeutic effect, irrespective of any prescribed drug or treatment. Z. Di Blasi, E. Harkness, E. Ernst, A. Georgiou and J. Kleijnen (Blasi, Z. Di, Harkness, E., et al, 2021) carried out a systematic review to determine if there is any empirical evidence to support this theory. Scientists have developed a comprehensive search strategy to include 11 medical, psychological, and sociological electronic databases. Cognitive and emotional help were categorised separately. Cognitive care aims to influence patients' expectations about the illness or the treatment, whereas emotional care refers to the style of the consultation, and aims to reduce negative feelings such as anxiety and fear. The authors identified much inconsistency regarding emotional and cognitive care, but one consistent finding is that physicians who adopt a warm, friendly, and reassuring manner are more effective than those who keep consultations formal and do not offer reassurance. A review of publications conducted by Isabel Taveira-Gomes, Rui Mota-Cardoso, Margarida Figueiredo-Braga (2016) on medical students' communication skills shows the effective communication being the cornerstone of patient-centered medicine and empathic behavior leading to a fruitful patient-physician relationship. This contributes to a positive therapeutic effect and better results and patient satisfaction, thereby improving the overall quality of healthcare (Taveira-Gomes, I., Mota-Cardoso, R., \& Figueiredo-Braga, M., 2016).

M.A. Stewart (Stewart M.A., 1995) analyzed the publications using "doctor-patient relationship" as the main title for the medical researchers in the MEDLINE bibliographic database (articles published from 1983 to 1993), as well as several bibliographies and conference materials. Most of such surveys revealed a correlation between the effective doctor-to-patient communication and progress for a patient's health. The quality of communication when collecting the anamnesis during medical encounters as well as during the treatment discussion is sure to affect the treatment of patients. A longitudinal study of third-year medical students' communication competence, communication anxiety, and attitudes toward patient-centered care by A.M. Kerr, C. M. Thompson (2021), shows that students' competence and anxiety regarding communication during medical encounters improved by the third year of training and largely depended on their attitude and orientation to patient-centered treatment and communication. The authors believe that the curriculum of medical students should contribute to the formation of a positive attitude towards patient-centered communication and provide an opportunity to practice complex communication skills for improving competence. The authors recognize that patient-centered communication is an important clinical skill.

The study of the role of emotional competencies in predicting the attitude of medical students' attitudes towards communication skills training, conducted by H. Givron and M. Desseilles (2021), showed that since the context of medical consultation encourages discussion of various emotions experienced by the patient, the process of teaching medical students should prepare students for this.

A study by J.B. Plotkin, R. Shochet (2018) revealed that first-year medical students encountered challenges in learning empathic communication, and patients might perceive empathy from students in ways other than verbal responses. Curricula should focus on assisting students with anxiety of multi-tasking, sense of vulnerability, buy-in to communications training, and the importance of non-verbal communication, and form an interest in learning communication skills and the importance of non-verbal communication. A deliberate focus on empathetic responsiveness, especially non-verbal, might lessen anxiety, improve attentional switching, and build confidence in managing vulnerability for early medical students learning communication skills.

Considering the problems of the medical specialists humanitarian competencies, Taratukhin E. O. (Taratukhin E. O., 2019) emphasizes that working with a person requires a doctor to have competencies other than treating biologically the pathology, and time seems to come to distinguish "biomedical doctors" and "medical doctors" in clinical medicine, meanwhile the first are not required to have humanitarian 
competencies. Since non-infectious pathology is largely psychosomatic in nature, and mental processes are filled with the experience of social reality, a practical clinician must be skilled in human sciences, having such competencies as: skills of internal work, situational search and interpretation, communicative and ethical competence, the promotion of positive health.

The ability to interact with people, the development of communication skills (communicative competence), knowledge, features of professional thinking, personal qualities seem to be important components of the activity of a medical specialist, as for R.M. Abdulgalimov's take (Abdulgalimov R.M., 2013). The professional competence of a medical specialist includes special medical training, universal culture, the system of values, and communicative literacy. The communicative competence of a medical specialist in a professional field includes understanding and interpretation of professional terms, concepts (for example, in conversing with colleagues, doctors of different specialties, nurses and those who are far from medical science); understanding verbal, formal (formulas, pictures of the functioning of various organs) and non-verbal means (facial expressions and gestures in conversation with a patient); skillful handling of specially prepared material (graphs, X-rays and pictures).

Trushkina S.V. (Trushkina S.V., 2018) notes that modern models of interaction look the general purpose of medical care more broadly than before, not only as the ability to work but as preservation and improvement of human life quality. Partnership means a fairly high openness and communicative competence of the doctor. The ability to professionally arrange the process of communication with the patient is no longer the category of desirable personal traits of the doctor, it is the working skill. Empirical research data show that modern patients expect doctors to be able to please the interlocutor, answering his questions in the simple language, giving an opportunity to express a different opinion, etc. However, the real behavior of doctors in a large percentage of cases does not meet these expectations, which negatively affects the level of interaction with patients in their own healing process. Thus, the appearance of doctors following the principles of partnership and specific methods of a professional conversation is an urgent task. The author emphasizes that in Russian professional training programs for doctors and nursing staff, getting professional communication skills is not given sufficient attention. The author explores the technique of active listening, emotional support to the patient or his family, constructive overcoming the resistance of the interlocutor, the ability to limit the use of professional vocabulary in conversation and effectively provide the necessary information. These communicative skills are vitally important for the doctor.

Considering the importance of communicative competencies in the professional training of a doctor, (Petunova S.A., 2014) in the publication "On the formation of a doctor's communicative competence in professional activity" states that at present research on the communication process as the main element of professional activity is of particular importance, communication being the key to the professional success and effectiveness.

A number of problematic issues on the communicative competence of senior medical students are highlighted in the study of Lysova D.P., Lysova M.P. (Lysova, D.P., Lysova, M.P., 2017), 88\% of respondents rating their training in communication technologies as high and sufficient, but knowledge of theoretical questions does not always meet the requirements of today. Thus, only $87 \%$ of future doctors considered it necessary to say hello to the patient and $46 \%$ - to introduce themselves while starting the appointment. More than $60 \%$ of students were ready to interrupt the patient during the consultation, and more than $15 \%$ considered the patient's concerns not worthy of attention. More than $23 \%$ of respondents admitted concealing information about an incurable disease or reporting it only to the patient's family, which can entail serious legal consequences for the medical organization and the doctor himself. The study revealed that more than half of respondents consider low communicative competence to be the main reason for complaints against medical workers (rudeness, inattention of medical personnel, lack of mutual understanding with the patient's family, inability of the doctor to establish contact with the patient, removal of the patient and his family from deciding on the choice of diagnostic and therapeutic procedures). The present research aims to study the psychological features of the communicative competence of medical university students, considered within the framework of the proposed approach, through the features of emotional intelligence, coping strategies, the level of communication skills.

The purpose of this study was to study psychological readiness to doctor-patient communication in medical students' professional development.

\section{METHODS}

The research was conducted at the Russian regional university, Cheboksary, Russian Federation. The study involved total sample size of 120 medical students (1st and 2 nd year students, age 19.2 \pm 2.6 ) with a high 
academic performance, the interviews with teachers and analysis of documentation (learning performance, academic records: 84 of them being girls and 36 boys).

While making a research the following methods were used: analysis of scientific sources, methods of mathematical and statistical data processing (methods of descriptive statistics, correlation analysis), testing, interviews, documentation analysis.

The following psychodiagnostic techniques were used:

1. Communication Skills assessment test (Psychological tests, 2001);

2. Hall's Emotional Intelligence Quotient (Ilyin E.I., 2010);

3. R. Lazarus' "Ways of Coping Questionnaire” (Kryukova T.L., Kuftyak E.V., 2007).

The following methods were used as psychodiagnostic tools at the empirical stage:

1. Test of assessment of communicative skills. The assessment is performed by calculating the percentage of statements with which the test subject agrees. The lower the percentage of such statements is, the higher is the level of communication skills of the test subject.

2. Hall's Emotional Intelligence Quotient test. The questionnaire consists of 30 items, the answers being ranged on a 6-point scale. The points make 5 scales, each of them containing 6 points, the points of the scales do not overlap: emotional awareness; managing your emotions (emotional responsiveness, emotional rigidity); self-motivation (arbitrary control of your emotions); empathy; recognition of other people's emotions (as the ability to influence the emotional state of other people).

3. "Ways of Coping Questionnaire" by R. Lazarus. The questionnaire consists of 50 responses grouped into 8 scales: "Confrontation", "Distancing", "Self-controlling", " Seeking social support ", " Accepting responsibility ", "Escape-avoidance", " Planful problem solving ", " Positive reappraisal ".

\section{RESULTS}

The results of the conducted test for assessing the communicative skills of medical students show the results of studying the communicative characteristics of medical students using the method of "Test of assessment of communicative skills". The average on this scale is of 7.33 and a standard deviation is of $4.81(7.33 \pm 4.81)$. The test subjects were divided according to the manifestation of the measured tag.

According to the "Test of assessment of communicative skills" method, a higher indicator means low communication skills, thus, highly developed communication skills have 21 test subjects (17.5\%) have high communication skills, $55(45.83 \%)$ are below average, 37 (30.83\%) are above average, which is the majority, and 7 tested $(5.83 \%)$ have low communication skills.

Thus, we can say that most sample students have such a communicative tolerance in which they have no intension to feel strong hostility in communicative situations with an interlocutor violating the delicacy in conversation, while they tend to make hasty conclusions about the interlocutor, focus on the manner of speaking, look for the hidden sense.

The study of emotional intelligence of medical students according to the method "Hall's Emotional Intelligence Quotient" showed that for the formation extent, the components of emotional intelligence of medical students were distributed as follows:

- In the first place, i.e. most pronounced in medical students "Emotional awareness» is awareness and understanding of one's own emotions, and for this, constant replenishment of one's own vocabulary of emotions. People with high emotional awareness are more aware of their inner state than others.

- In second place in terms of severity: "Empathy» is an understanding of other's emotions, the ability to empathize with the current emotional state of another person, as well as a willingness to provide support. This is the ability to understand a person's mood by facial expressions, gestures, speech nuances, posture.

- In the third place: «Recognizing other's emotions» - the ability to influence the emotional state of other people.

The next was: Self-motivation - behaving yourself by controlling emotions.

Lowest results were - «Mastering your emotions» is emotional responsiveness, emotional flexibility, etc., in other words, arbitrary management of one's emotions. 
Table 1. Rate of emotional intelligence of medical students according to the method "Hall's Emotional Intelligence Quotient"

\begin{tabular}{|c|c|c|c|c|c|c|c|c|c|c|}
\hline \multirow[b]{3}{*}{ Rate } & \multicolumn{10}{|c|}{ Scales } \\
\hline & \multicolumn{2}{|c|}{$\begin{array}{l}\text { Emotional } \\
\text { awareness }\end{array}$} & \multicolumn{2}{|c|}{$\begin{array}{l}\text { Mastering your } \\
\text { emotions }\end{array}$} & \multicolumn{2}{|c|}{$\begin{array}{l}\text { Self- } \\
\text { motivation }\end{array}$} & \multicolumn{2}{|c|}{ Empathy } & \multicolumn{2}{|c|}{$\begin{array}{l}\text { Recognizing other's } \\
\text { emotions }\end{array}$} \\
\hline & $\begin{array}{l}\text { abs. } \\
\text { pers. }\end{array}$ & $\%$ & $\begin{array}{l}\text { abs. } \\
\text { pers. }\end{array}$ & $\%$ & $\begin{array}{l}\text { abs. } \\
\text { pers. }\end{array}$ & $\%$ & $\begin{array}{l}\text { abs. } \\
\text { pers. }\end{array}$ & $\%$ & $\begin{array}{l}\text { abs. } \\
\text { pers. }\end{array}$ & $\%$ \\
\hline low & 19 & 21.84 & 30 & 34.48 & 20 & 22.99 & 21 & 24.14 & 22 & 25.29 \\
\hline $\begin{array}{l}\text { aver } \\
\text { age }\end{array}$ & 35 & 40.23 & 58 & 66.67 & 44 & 50.57 & 41 & 47.13 & 37 & 42.53 \\
\hline hig & 66 & 75.86 & 32 & 36.78 & 56 & 64.37 & 58 & 66.67 & 61 & 70.11 \\
\hline
\end{tabular}

The results presented in Table 1 make it possible to conclude that the majority of medical students participating in the study have high scores on the scales of "Emotional awareness", "Self-motivation", "Empathy", "Recognition of other's emotions", as well as average scores on the scale of "Mastering your emotions".

The results of the study conducted on the Lazarus' "Ways of Coping Questionnaire" are presented in Table 2.

Table 2. Results of studying the features of coping behavior of students according to the "Ways of Coping Questionnaire" by R. Lazarus

\begin{tabular}{|c|c|c|c|c|c|c|c|c|c|}
\hline \multicolumn{2}{|c|}{ Test subjects } & 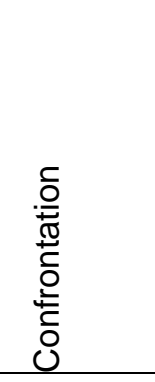 & 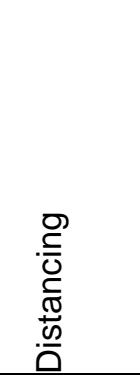 & 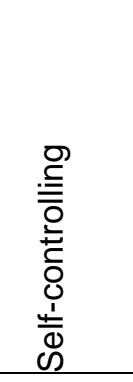 & 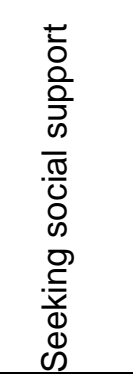 & 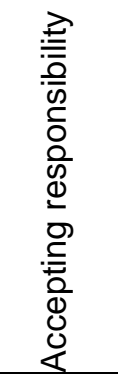 & 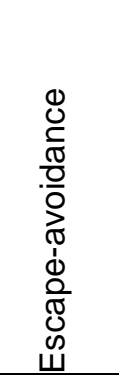 & 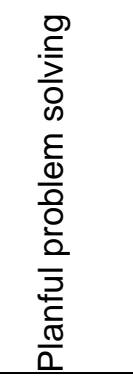 & 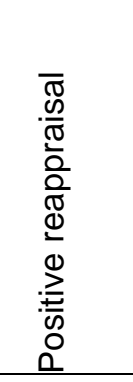 \\
\hline \multirow{3}{*}{$\begin{array}{l}\text { Medi } \\
\text { cal } \\
\text { stude } \\
\text { nts }\end{array}$} & average & 8,25 & 9,08 & 11,46 & 9,60 & 7,07 & 11,93 & 10,98 & 11,90 \\
\hline & $\begin{array}{l}\text { Standard } \\
\text { deviation }\end{array}$ & 2,96 & 3,33 & 3,77 & 3,57 & 2,60 & 4,49 & 4,06 & 4,20 \\
\hline & Rate & 7 & 6 & 3 & 5 & 8 & 1 & 4 & 2 \\
\hline
\end{tabular}

The rate of representation of coping behavior strategies for the medical students is as follows:

Escape-avoidance $(11.93 \pm 4.49)$ By most researchers, this strategy is non-adaptive, but this does not exclude its use in certain situations, especially in the short-time projects and in acute stressful situations. Such a strategy in overcoming negative experiences caused by difficulties occurs due to the type of evasion response: denial of the problem, fantasizing, unjustified expectations, distraction, etc. People with this pronounced strategy may have unconstructive behaviors in stressful situations: denial or complete disregard of the problem, escaping from responsibility or resolving difficulties, passiveness, impatience, outbursts of irritation, immersion in fantasies, overeating, alcohol abuse, etc., in order to reduce painful emotional stress. The steady application of such a strategy may result in non-possible solving the problem, the accumulation of difficulties, only a short-term effect of measures to reduce emotional discomfort. 
Positive reappraisal $(11.90 \pm 4.20)$. The strategy of positive reappraisal involves overcoming the negative experiences caused by the problem due to its positive rethinking, considering it as an incentive for personal growth. A person reconsiders the problem, includes it in the broader context of self-development, getting the opportunity to positively rethink the situation. The negative side of such a coping strategy is a probable underestimation of an effective solution to a problematic situation.

Self-controlling (11.46 \pm 3.77$)$. This strategy involves overcoming negative experiences caused by the problem by purposefully suppressing and restraining emotions, minimizing their influence on the assessment of the situation and the choice of a behavior strategy, high behavior control, striving for self-control. People with such a preferred strategy may have a fear of self-disclosure, excessive demands on themselves, leading to over-control of behavior, which may result in difficulties when expressing feelings, needs and motives in the context of a problem, over-control of behavior.

Planful problem solving (10.98 \pm 4.06$)$. Most researchers consider this strategy as adaptive, contributing to constructive resolution of difficulties. Such a strategy is associated with an attempt to overcome the problem by purposefully analyzing the situation and possible behaviors, developing a strategy for solving the problem, planning your own actions taking into account objective conditions, past experience and available resources. This strategy has its drawbacks associated with excessive rationality and insufficient emotionality and spontaneity, intuitiveness.

Seeking social support $(9.60 \pm 3.57)$. Searching for predominantly effective support is caused by the need for specific assistance. Positive aspects: the ability to use external resources. The strategy of finding social support involves attempts to solve the problem by attracting external (social) resources, searching for informational, emotional and effective aid. The features are the interaction with other people, expectation of attention, advice, and sympathy. The search for mainly informational support involves seeking recommendations from experts and acquaintances who, from the respondent's point of view, possess the necessary knowledge. The need for emotional assistance is mainly manifested by the desire to be listened to, to receive an empathic response, to share the emotions with someone.

Distancing (9.08 \pm 3.33$)$. The distancing strategy involves overcoming negative experiences caused by the problem by subjectively reducing its significance and the emotional involvement in it. Its feature is using the intellectual techniques of rationalization, attention switching, detachment, humor, depreciation, etc. Positive aspects: the possibility of reducing the subjective significance of intractable situations and preventing intense emotional reactions to frustration. Negative aspects: the probability of devaluation of one's own experiences, underestimation of the significance and possibilities of effective overcoming of problematic situations.

Confrontation ( $8.25 \pm 2.96$ ) Such a strategy is usually proposed to be considered as maladaptive, but with moderate use it can provide a person's ability to resist difficulties, energy and initiative in solving problematic situations, the ability to defend one's own interests, cope with anxiety in stressful conditions. Such a strategy manifests itself in solving the problem through not always purposeful behavioral activity, the implementation of specific actions aimed either at changing the situation or responding to negative emotions caused by the difficulties. The pronounced preference for this strategy may lead to impulsivity in behavior (sometimes with elements of hostility and conflict), hostility, difficulties in planning, predicting the results, correcting behavior strategies, unjustified perseverance can be evident. Positive aspects: the possibility of actively resisting difficulties and stressful effects. Negative aspects: insufficient purposefulness and rational justification of behavior in a problematic situation.

Accepting responsibility $(7.07 \pm 2.60)$. This strategy involves the recognition by the subject of his own role in the problem and responsibility for its solving, in some cases with a distinct component of self-criticism and self-blame. At the same time, preferring this strategy may result in unjustified self-criticism, feelings of guilt and dissatisfaction with oneself and become a risk factor for the depressiveness. Positive aspects: understanding the personal role of why the problems occur. Negative aspects: unjustified self-criticism and excessive responsibility. With moderate use, this strategy reflects the individual's aim to understand his own activity and its consequences, the willingness to analyze his behavior, to look for the reasons of difficulties in personal shortcomings and mistakes.

Then a correlation analysis was carried out using the Pearson correlation method of the studied indicators: the scales of the Lazarus "Ways of Coping Questionnaire" and the scales of the Hall's Emotional Intelligence Quotient; the results of the Communication Skills assessment test (indicated by the abbreviation "TOKU").

The analysis of significant relationships of the "Ways of Coping Questionnaire" scales and the scales of the Emotional Intelligence Quotient, the test of assessment of communicative skills for medical students 
revealed:

According to the "Test of assessment of communicative skills" method, a higher indicator means low communication skills, thus, highly developed communication skills have significant positive correlations with a scale such as "Escape-avoidance" $(r=0,29, p<0.01)$ and with a scale of "Confrontational coping" $(r=0,25$, $p<0.01)$; positive correlations with a scale of " Distancing" $(r=0,19, p<0.05)$ and with a scale of «Selfcontrolling»" $(r=0,18, p<0.05)$;

For the Emotional Intelligence test scales, significantly reliable positive correlations were identified with the following scales of Ways of Coping Questionnaire".

"Emotional awareness" with coping strategies $(p<0.001)$ with such Ways of Coping Questionnaire" scales as: "Accepting responsibility", "Planful problem solving", "Escape-avoidance", "Positive reappraisal", "Seeking social support", "Self-controlling", "Distancing", "Confrontation".

For the "Mastering your emotions" scale, significant correlations $(p<0.01)$ were found with the coping strategies "Positive reappraisal" $(r=0,44, p<0.001)$ and "Planful problem solving" $(r=0,43, \quad p<0.001)$; "Confrontation" ( $r=0,15, p<0.05)$; with the coping strategies "Distancing" $(r=0,19, p<0.05)$; "Self-controlling" $(r=0,26, p<0.01)$. Such a correlation can be explained by the fact that mastering your emotions is a necessary ability in order to be able to abstract from problematic experiences and devote time to solving the problem itself, to be able to find positive sides in difficult situations. Also, motor activity can be used as a way to cope with anxiety.

The "Self-motivation" scale has correlations $(p<0.01)$ with the coping strategies "Confrontation", "Distancing", "Accepting responsibility", "Self-controlling", "Seeking social support ", "Planful problem solving" and "Positive reappraisal". These results can be explained by the ability to arbitrarily control one's emotions that makes it preferable for a person to reduce the significance of the problem and rethink it from a positive side, which helps to start planning a solution soon.

The Empathy scale has correlations $(p<0.001)$ with coping strategies "Planful problem solving", "Positive reappraisal", "Confrontation", "Distancing", "Self-controlling", "Seeking social support", "Accepting responsibility"; $(p<0.05)$ with coping strategies "Escape-avoidance". The high correlation of «empathy» and coping strategies due to problem-solving planning may be caused by the fact that a large part of problems is often associated with the presence of a human factor and in order to think through the solutions to the problem, it is necessary to be able to predict and understand the behavior of others, as well as adjust to the social context, which presumably gives a greater range of available coping mechanisms.

The scale "Recognizing emotions of others" has a correlation $(p<0.001)$ with coping strategies "Confrontation", "Distancing", "Self-controlling", "Seeking social support", "Accepting responsibility", "Planful problem solving", "Positive reappraisal"; $(p<0.01)$ with the scale "Escape-avoidance". The high correlation of the ability to influence the emotions of other people with awareness of their role in a problem situation and planning a solution to the problem can be explained by the fact that people who are inclined to leadership are also capable of taking responsibility for what happened and organizing a solution to the problem.

\section{CONCLUSIONS}

The analysis of publications has shown that the majority of foreign researchers emphasize the significant role of communicative competence in professional interactions of doctor-patient communication. Russian researchers are less similar in their high assessment of this role, believing that communicative competence (humanitarian competencies) is not needed by a part of doctors working with pathology at the biological level, while agreeing on the need to have highly developed communicative skills in doctor-patient communication for doctors who directly interact with patients.

The results of the study made it possible to obtain an up-to-date understanding of psychological readiness for doctor-patient communication in the professional development of medical students. Based on the results of the study, a fairly large proportion of university students of medical specialty who took part in the study needs further development of their communicative competence in their formation as a future professional in the field of medicine: the proportion of students with certain communication difficulties is significant (about $50 \%$ ); there are students with low levels of emotional intelligence on all scales; there are students with nonadaptive coping strategies that can become ineffective in overcoming negative experiences.

Information about the identified "psychocorrectional targets" is proposed for use to improve the psychological readiness to doctor-patient communication in the preparation of university students of a medical profile, as 
well as for organizing scientific and extra-curricular work with them.

\section{REFERENCE LIST}

Abdulgalimov, R. M. (2013).Communicative competence of a medical specialist as a component of professional activity. The world of science, culture, education. Vol. 4 (41). pp.77-79.

Blasi, Z. Di, Harkness, E., Ernst, E., Georgiou, A., Kleijnen, J. (2001). Influence of context effects on health outcomes: a systematic review. Lancet, 357, pp. 757-762. doi: 10.1016/s0140-6736(00)04169-6

Givron, H., Desseilles, M. (2021). The role of emotional competencies in predicting medical students' attitudes towards communication skills training. Patient Education and Counseling. https://doi.org/10.1016/j.pec.2021.03.015

Ilyin, E I. (2001) Emotions and feelings. St. Petersburg: Peter, 633-634.

Kerr, A.M., Thompson, C.M. (2021). A longitudinal study of third-year medical students' communication competence, communication anxiety, and attitudes toward patient-centered care. Patient Education and Counseling. https://doi.org/10.1016/j.pec.2021.09.004.

Kryukova, T L., Kuftyak, E V. (2007) Ways of Coping Checklist (adaptation of the WCQ methodology). Journal of a Practical Psychologist. Vol. 3, 93-112.

Lysova, D.P., Lysova, M.P. (2017). Assessment of the communicative competence of medical university students. Bulletin of Medical Internet Conferences, Vol.6. pp. 812-814.

Macnamara, J. (2018). Competence, competencies and/or capabilities for public communication? A public sector study. Asia pacific public relations journal. Vol. 19 , pp.16-40.

Morova, N.S., Zakharova, A.N., Talanova, T.V., Dulina, G.S., Kadyshev, E.N. (2017). Peculiarities of professional formation of students of psychological specialties of different forms of education at the stage of higher education. Proceedings of the 30th International Business Information Management Association Conference, IBIMA 2017 - Vision 2020: Sustainable Economic development, Innovation Management, and Global Growth. pp. 5522-5527.

Morova, N.S., Zakharova, A.N., Talanova, T.V., Dulina, G.S., Nikolaev, E.L. (2017) Psychology of personal competitiveness of students in the system of higher education. Proceedings of the 30th International Business Information Management Association Conference, IBIMA 2017 - Vision 2020: Sustainable Economic development, Innovation Management, and Global Growth. Pp.4460-4468.

Nasilenko, L.A. (2013). Formation of the communicative competence of future lawyers in a higher educational institution (from the experience of the university of modern knowledge). Karelian scientific journal. 2013. No. 4 (5). S. 31-33

Petrovskaya, A.S. (2007). Emotional intelligence as a determinant of effective parameters and procedural characteristics of managerial activity: Abstract of a thesis. ... psychol. sciences. Yaroslavl. 2007.

Petunova, S.A. (2014). On the formation of a doctor's communicative competence in professional activity. Issues of improving the effectiveness of vocational education in modern conditions. Materials of the VI International. studies.- method. conf. pp. 252-257.

Plotkin, J. B., Shochet, Robert (2018) Beyond words: What can help first year medical students practice effective empathic communication? Patient Education and Counseling. https://doi.org/10.1016/j.pec.2018.07.013

Solovieva, O. V., Bondarenko, O.S. (2018). Emotional intelligence in the structure of professionally important qualities of a psychologist of various professional orientations. Problems of modern teacher education. Vol. 60-4. pp. 465-468.

Stewart, M.A. (1995). Effective physician-patient communication and health outcomes: a review. CMAJ, 152, pp. 1423-1433. 
Taratukhin, E. O. (2019). Humanitarian competencies of a doctor (cardiologist). Russian Journal of Cardiology. Vol.9. pp.28-32.

Taveira-Gomes, I., Mota-Cardoso, R., \& Figueiredo-Braga, M. (2016). Communication skills in medical students - An exploratory study before and after clerkships. Porto Biomedical Journal, 1 (5). doi: 10.1016/j.pbj.2016.08.002

The Psychological Tests / Edited by A.A. Karelin: In 2 vol. M., 2001. Vol. 2, pp. 50-53.

Tretyakov, V.S., Ignatenko, A.A. (2012). Communicative competence of the future teacher: concept, essence and structure. Bulletin of the Chelyabinsk State Pedagogical University. Vol. 1.P. 217-230.

Trushkina, S.V. (2018). Challenges of modernity: medical compliance, partnerships, communicative competence of a doctor. Medical psychology in Russia. 2018. Vol.4. p.7.

Zakharova, A., Talanova, T., Dulina, G., Semenov, V., Getskina, I., Semenova, N. (2018) Psychological features of competitiveness of university students. The European Proceedings of Social \& Behavioural Sciences EpSBS. Vol. L. pp.1416-1423. doi:https://dx.doi.org/10.15405/epsbs.2018.12.173

Zakharova A., Nikolaev E., Hartfelder D., Dulina G., Lazareva E., Talanova T. Psychological Features of Attitude Towards Health and Violation of Healthy Lifestyle in Russian University Students.

Proceedings of the 36th International Business Information Management Association (IBIMA), (4-5 November 2020, Granada, Spain). Pp. 3772 -3783 